\title{
NUTRITIONAL, METABOLIC AND CARDIOVASCULAR CORRELATIONS OF MORNING CORTISOL IN HEALTH CARE WORKERS IN A GASTROENTEROLOGY SERVICE
}

\author{
Aline GUERRA ${ }^{1}$, Rafael Marques SOARES ${ }^{1}$, Fernanda PEZZI ${ }^{1}$, \\ Francisco Juarez KARKOW ${ }^{1}$ and Joel FAINTUCH ${ }^{2}$
}

\begin{abstract}
Background - Workplace stress has been associated with obesity. Diminished body weight has also been anticipated in some contexts. Objective - In a cohort of healthcare personnel, morning cortisol was compared to nutritional and metabolic variables, aiming to identify the correlates of such marker. Methods - Population n=185, $33.8 \pm 9.8$ years, $88.1 \%$ females, body mass index (BMI) $25.6 \pm 4.4 \mathrm{~kg} / \mathrm{m}^{2}$, included nurses and other nosocomial professionals, the majority with high social-economic status (75.2\%). Participants were stratified according to BMI, fasting blood glucose (FBG) and metabolic syndrome (MS). Fasting plasma cortisol and the Framingham Coronary Risk Score was calculated. Results - Mean cortisol was acceptable $(19.4 \pm 7.9 \mu \mathrm{g} / \mathrm{dL})$ although with elevation in $21.6 \%$. No correlation with FBG or MS occurred, and nonobese persons (BMI <25) exhibited the highest values $(P=0.049)$. Comparison of the lowest and highest cortisol quartiles confirmed reduced BMI and waist circumference in the former, with unchanged Framingham Coronary Risk Score. Conclusion - Cortisol correlated with reduced BMI. Despite low BMI and waist circumference, Framingham Coronary Risk Score was not benefitted, suggesting that exposure to cardiovascular risk continues, besides psychological strain. Initiatives to enhance organizational and staff health are advisable in the hospital environment.
\end{abstract}

HEADINGS - Hydrocortisone. Metabolic diseases. Obesity. Health personnel. Professional burnout.

\section{INTRODUCTION}

Obesity and its comorbidities have become a universal public health concern, in most white-collar environments, however socially disadvantadged populations, especially women, are not less affected ${ }^{(5)}$. Stressful events are often blamed as triggers of energy homeostasis rupture such as divorce, personal conflicts and financial losses, yet overwork and burn out are analogously incriminated ${ }^{(6)}$. Decreased body weight is nowadays a rare occupational complication, yet links can be recognized as well, on account of workplace strain itself ${ }^{(14)}$.

Institutional health care activities mostly involve female white-collar personnel, and occupational exposure to psychological pressure and discomfort is not negligible, given the complex demands, strict hierarchy, limited decision latitude, high responsibilities, and stringent deadlines. Aberrant eating patterns and other obesity precipitating changes have been reported in stressed nurses ${ }^{(9,12,31)}$, in parallel with elevation in cortisol secretion ${ }^{(24)}$. Nevertheless, decrease or delay in morning peak cortisol is also acknowledged after night shift, in emergency physicians ${ }^{(17)}$.

A survey of 160,000 European conventional workers, confirmed an association between self-reported job strain and obesity, however also underweight was highlighted as a risk. in the same circumstances ${ }^{(23)}$. Military women exposed to combat conditions, were conspicuously more likely to lose $10 \%$ or more of their body weight ${ }^{(13)}$. Serum cortisol was not monitored in these epidemiological studies.

Psychosocial stress may be relevant as well for cardiovascular risk, with emphasis on mortality ${ }^{(3,28)}$, besides the impact on psychological discomfort and quality of life ${ }^{(18)}$.

Given the importance of the topic, and the conflicting reports on cortisol changes as well as body weight consequences, a study was designed to analyze the association between morning plasma cortisol,

Department of Nutrition, Faculdade Nossa Senhora de Fátima, Caxias do Sul, RS. ${ }^{2}$ Hospital das Clínicas, São Paulo, SP. Brazil.

Correspondence: Prof. Joel Faintuch. Hospital das Clínicas, ICHC, $9^{\circ}$ andar, sala 9077. Av. Enéias C. Aguiar, 255 - CEP: $05403-900$ - São Paulo, SP, Brasil. E-mail j.faintuch@hc.fm.usp.br 
and risk factors in the hospital team. To the best of our knowledge, this is the first investigation within such context including nutritional, metabolic and cardiovascular markers.

\section{METHODS}

\section{Experimental design and enrollment}

This was a prospective, observational clinical study. Participants were consecutively recruited, among the personnel of a midsize private academic hospital, and clinically interviewed, subsequently undergoing biochemical assessment, without any intervention. This protocol was approved by the institutional Ethical Committee of Fatima Faculty (084/2011), and all subjects gave written informed consent.

\section{Population}

Given a total healthcare workforce of $465,44.5 \%$ (207/465) were randomly selected and 187 included, based on a effect size of $8 \%$ and power of $95 \%$. Criteria of inclusion were age 20-60 years, males and females, with any professional qualification. Criteria of exclusion were sick leave or retirement, pregnancy, lactation, organ failures, transplantation, HIV/AIDS, tuberculosis or other consumptive illness, Cushing's disease, use of corticosteroids for Crohn's disease, allergy or other conditions, psychiatric treatment, and refusal to participate in the study.

\section{Definitions and stratification}

DM and prediabetes were diagnosed according to the 2010 criteria of the American Diabetes Association ${ }^{(2)}$. An individual was considered to have DM if receiving pharmacologic prescription, or with a fasting blood glucose (FBG) $\geq 126 \mathrm{mg} / \mathrm{dL}$. Prediabetes was identified by impaired fasting glucose $(100-125 \mathrm{mg} / \mathrm{dL})$, with or without medication. Characterization of metabolic syndrome (MS) followed the guidelines of the International Diabetes Federation ${ }^{(1)}$, namely central obesity (waist circumference $\geq 94 \mathrm{~cm}$ for men and $\geq 80$ $\mathrm{cm}$ for women), plus two of the following: serum triglyceride $\geq 150 \mathrm{mg} / \mathrm{dL}$, HDL cholesterol $<40 \mathrm{mg} / \mathrm{dL}$ for men and $<50$ $\mathrm{mg} / \mathrm{dL}$ for women, systolic $\mathrm{BP} \geq 130 \mathrm{mmHg}$ or diastolic BP $\geq 85 \mathrm{mmHg}$, and FBG $\geq 100 \mathrm{mg} / \mathrm{dL}$. These same criteria along with BMI were adopted for stratification.

\section{Clinical interview}

Demographic information, along with clinical history relevant to stratification variables and criteria of exclusion, was gathered. Participants were asked whether they were smokers, performed regular physical activities, and had family history of coronary disease. The Framingham Coronary Heart Disease Risk Score (FCRS) was calculated according to age, gender, TC, HDL-C, blood pressure, diabetes, and smoking ${ }^{(30)}$.

\section{Biochemical variables}

FBG, lipid fractions and fasting serum cortisol were part of the protocol. Blood samples were collected on weekdays in the morning, subsequent to overnight fast. Patients were instructed to arrive at the hospital about 30 minutes after awakening, having abstained from alcohol, caffeinated beverages and physical exercise since the previous evening. Samples were expediently drawn, stored on ice, and processed by a modular analytical system, including plasma cortisol which was determined by chemiluminescence immunoassay, in the same institution (Bayer Diagnostics, Sao Paulo, Brazil). The inter- and intra-assay coefficient of variation was under $8 \%$ for this hormone.

\section{Statistical analysis}

Numerical variables were compared by Student's $t$ test or by analysis of variance (ANOVA) and post-hoc Bonferroni test, employing $\log$ transformation of cortisol findings because of skewed distribution. Chi Square test was used for discrete variables. Linear regression (Pearson) as well as multivariate analysis (backward step-wise selection logistic regression) was selected for correlations, corrected for covariates (age, gender, smoking, sedentarism). Difference between the lowest and highest cortisol quartiles was calculated using the log-rank test.

The Statistical Package for the Social Sciences, version 16 (2007), was used, and differences were considered significant when $P$ value was less than 0.05 .

\section{RESULTS}

This was a comparatively young cohort $(33.8 \pm 9.8$ years), predominantly female $(88.1 \%, 163 / 185)$ and mildly overweight $\left(25.6 \pm 4.4 \mathrm{~kg} / \mathrm{m}^{2}\right)$. A majority with high social-economic status was noticed $(75,2 \%, 139 / 185)$, with a predominance of nurses, however including multiple occupations. Nonsmokers reached $82.7 \%(153 / 185)$, sedentarism was highly prevalent $(77.8 \%, 141 / 185)$, and nearly half confirmed coronary heart disease in the family $(47.0 \%, 87 / 185)$. This profile did not coincide with the demographics of the regional population $^{(7)}$, indicating a cohort of higher educational and economic position. Principal features after stratification according to BMI are depicted in Table 1.

As expected obese participants suffered from a more deranged glucose and lipid profile, even if mostly within the normal range, and also blood pressure and FCRS were higher. Mean cortisol values were acceptable, although 21.6\% (40/185) exceeded the upper limit of normality $(5-25 \mathrm{ug} / \mathrm{dL})$. The lowest results corresponded to the obese cohort.

Participants were stratified on the basis of glucose homeostasis and metabolic syndrome status (Tables 2 and 3). Again those more metabolically deranged exhibited a less healthy clinical profile, including increased FCRS. Cortisol expression did not match such abnormalities, as no differences materialized.

Analysis according to gender did not reveal different cortisol concentrations, or conflicting correlations between males and females (results not shown).

Univariate regression analysis indicated that cortisol concentration was negatively linked to several obesity-related clinical and metabolic markers, and positively to HDL-cholesterol. Age, BMI and waist circumference were confirmed as independent variables, after multivariate analysis (Table 4). 
TABLE 1. Profile of the population according to BMI

\begin{tabular}{lcccc}
\hline Variable & BMI $<25$ & BMI 25-29.9 & BMI $\geq 30$ & Significance $P$ \\
\hline Age (years) & $32.3 \pm 8.8$ & $35.6 \pm 10.2$ & $35.6 \pm 11.7$ & $=0.196$ \\
Gender $(\%$ males) & $9.6 \%(9 / 94)$ & $14.8 \%(9 / 61)$ & $13.3 \%(4 / 30)$ & $=0.260$ \\
BMI $\left(\mathrm{kg} / \mathrm{m}^{2}\right)$ & $22.3 \pm 1.7$ & $27.0 \pm 1.5$ & $33.0 \pm 3.5$ & $<0.001$ \\
Waist $(\mathrm{cm})$ & $76.0 \pm 7.8$ & $85.8 \pm 6.1$ & $98.3 \pm 10.2$ & $=0.001$ \\
Systolic $(\mathrm{mmHg})$ & $117 \pm 13$ & $119 \pm 11$ & $126 \pm 15$ & $=0.041$ \\
Diastolic $(\mathrm{mmHg})$ & $74 \pm 9$ & $79 \pm 9$ & $92.1 \pm 21.4$ & $=0.013$ \\
FBG $(\mathrm{mg} / \mathrm{dL})$ & $81.1 \pm 8.6$ & $85.1 \pm 9.9$ & $193 \pm 42$ & $=0.285$ \\
Total chol. $(\mathrm{mg} / \mathrm{dL})$ & $184 \pm 33$ & $187 \pm 46$ & $51.7 \pm 15.1$ & $=0.047$ \\
HDL chol. $(\mathrm{mg} / \mathrm{dL})$ & $59.3 \pm 12.3$ & $52.4 \pm 13.6$ & $1.2 \pm 0.5$ & $=0.037$ \\
FCRS & $1.0 \pm 0.2$ & $1.1 \pm 0.2$ & $16.6 \pm 6.8$ & $=0.049$ \\
F cortisol $(\mu \mathrm{g} / \mathrm{dL})$ & $21.2 \pm 8.1$ & $18.0 \pm 7.4$ & & \\
\hline
\end{tabular}

BMI: body mass index; Waist: waist circumference; Systolic: systolic blood pressure; Diastolic: diastolic blood pressure; FBG: Fasting blood glucose; Total chol: total cholesterol; HDL chol: high density lipoprotein cholesterol; FCRS: Framingham Coronary Heart Disease Risk Score; F cortisol: fasting plasma cortisol.

TABLE 2. Profile of the population according to FBG

\begin{tabular}{|c|c|c|c|}
\hline Variable & FBG $<100$ & FBG 100-125 & Significance $P$ \\
\hline Age & $33.2 \pm 9.4$ & $41.7 \pm 12.0$ & $=0.003$ \\
\hline Gender ( $\%$ males) & $11.0 \%(19 / 172)$ & $23.1 \%(3 / 13)$ & $=0.041$ \\
\hline Waist (cm) & $82.4 \pm 10.1$ & $88.9 \pm 20.5$ & $=0.042$ \\
\hline Systolic (mmHg) & $118 \pm 13$ & $128 \pm 14$ & $=0.011$ \\
\hline FBG $\mathrm{mg} / \mathrm{dL}$ & $81.7 \pm 7.1$ & $110.7 \pm 8.6$ & $<0.001$ \\
\hline Total chol. (mg/dL) & $186 \pm 38$ & $199 \pm 58$ & $=0.173$ \\
\hline HDL chol. (mg/dL) & $56.4 \pm 13.5$ & $46.7 \pm 12.3$ & $=0.013$ \\
\hline FCRS & $1.06 \pm 0.26$ & $1.23 \pm 0.60$ & $=0.044$ \\
\hline F cortisol $(\mu \mathrm{g} / \mathrm{dL})$ & $19.5 \pm 7.9$ & $18.1 \pm 7.8$ & $=0.098$ \\
\hline
\end{tabular}

BMI: body mass index; Waist: waist circumference; Systolic: systolic blood pressure; Diastolic: diastolic blood pressure; FBG: Fasting blood glucose; Total chol: total cholesterol; HDL chol: high density lipoprotein cholesterol; FCRS: Framingham Coronary Heart Disease Risk Score; F cortisol: Fasting plasma cortisol.

TABLE 3. Profile of the population according to MS

\begin{tabular}{lccc}
\hline Variable & MS present & MS absent & Significance $P$ \\
\hline Age & $40.0 \pm 11.1$ & $32.6 \pm 8.9$ & $<0.001$ \\
Gender $(\%$ males $)$ & $6.9 \%(2 / 29)$ & $12.8 \%(20 / 156)$ & $<0.168$ \\
BMI $\left(\mathrm{kg} / \mathrm{m}^{2}\right)$ & $29.5 \pm 4.6$ & $24.8 \pm 4.0$ & $<0.001$ \\
Waist $(\mathrm{cm})$ & $92.3 \pm 11.3$ & $81.0 \pm 9.3$ & $<0.001$ \\
Systolic $(\mathrm{mmHg})$ & $127 \pm 14$ & $117 \pm 12$ & $<0.001$ \\
Diastolic $(\mathrm{mmHg})$ & $84 \pm 10$ & $82.3 \pm 9.1$ & $<0.001$ \\
FBG $\mathrm{mg} / \mathrm{dL}$ & $92.1 \pm 13.1$ & $182 \pm 34$ & $=0.002$ \\
Total chol. $(\mathrm{mg} / \mathrm{dL})$ & $209 \pm 53$ & $57.7 \pm 13.1$ & $<0.004$ \\
HDL chol. $(\mathrm{mg} / \mathrm{dL})$ & $46.0 \pm 11.8$ & $1.03 \pm 0.16$ & $=0.001$ \\
FCRS & $1.27 \pm 0.37$ & $19.7 \pm 7.9$ & $=0.336$ \\
F cortisol $(\mu \mathrm{g} / \mathrm{dL})$ & $18.2 \pm 7.8$ & & $=002$ \\
\hline
\end{tabular}

MS: metabolic syndrome; BMI: body mass index; Waist: waist circumference; Systolic: systolic blood pressure; Diastolic: diastolic blood pressure; FBG: fasting blood glucose; Total chol: total cholesterol; HDL chol: high density lipoprotein cholesterol; FCRS: Framingham Coronary Heart Disease Risk Score; F cortisol: fasting plasma cortisol. 
TABLE 4. Correlation indexes of fasting plasma cortisol

\begin{tabular}{lcc}
\hline Variable & Correlation $(\mathbf{r})$ & Significance $\boldsymbol{P}$ \\
\hline Age & -0.36 & $<0.001(*)$ \\
Waist circumference & -0.261 & $=0.004$ \\
BMI & -0.214 & $=0.013$ \\
Diastolic blood pressure & -0.141 & $=0.026$ \\
FBG & -0.129 & $=0.048$ \\
HDL cholesterol & 0.272 & $=0.002$ \\
FCRS & -0.133 & $=0.045$
\end{tabular}

(*) Age, BMI and waist circumference were confirmed by multivariate analysis. BMI: body mass index; FBG: Fasting blood glucose; HDL cholesterol: high density lipoprotein cholesterol; FCRS: Framingham Coronary Heart Disease Risk Score.

Aiming to confirm such profile, participants in the highest cortisol quartile were compared to those in the lowest one. Nutritional and metabolic differences concerning BMI, waist circumference and HDL-cholesterol emerged, the leaner subjects displaying the strongest cortisol response (Table 5).

\section{DISCUSSION}

Dysregulation of the hypothalamic-pituitary-adrenal axis (HPAA) has been highlighted in disorders such as anxiety, depression and obesity. Chronic exposure to cortisol, as a consequence of hyperactivity of the HPAA could trigger increased appetite, central obesity and insulin resistance, a context reminiscent of Cushing's syndrome ${ }^{(4,6,10,14,23,24)}$.

The concept of acute endocrine activation, also known as the fight or flight response, and involving not only cortisol but also epinephrine, norepinephrine and other mediators, has been advanced in the 1930's by Hans Selye, on the basis of classic rat models. Chronic experiments were equally conducted, confirming the dangers of unmitigated neuroendocrine challenge. Unsurprisingly, Selye considered this area "the most meaningful subject for humanity that I can think of"(26).

Since that era, much knowledge has accumulated in the domain of prolonged stress, targeting obesity, insulin resistance and diabetes, largely rooted in the role of cortisol in animal investigations. Clinical protocols ensued, however mainly utilizing questionnaires and self-rated stress, instead of hormone monitoring, because of convenience during epidemiological surveys. Harmonization of the two approaches has been attempted, however mismatches occasionally occur, as one addresses physiologic aggression, and the other perceived or emotional stress ${ }^{(11,17,22,23,31)}$.

One option to bypass such limitation is the cortisol awakening response (CAR), which represents the difference in cortisol concentration between waketime, and approximately 30 minutes afterwards. Cortisol peaks half an hout after waking, and the stronger the increase (CAR), the heavier the chronic perceived stress. For logistic reasons CAR could not be registered in this series, only the 30 minutes peak, however both are often related, and might be correlated with metabolic abnormalities ${ }^{(27)}$.

Despite the lack of CAR estimates in the current protocol, the biochemical stress model was preferred for the purposes of objectivity and reproducibility, as psychological stress and burn out have been assessed by a heterogeneous array of questionnaires, scales, instruments and inventories ${ }^{(11,17,22,23,31)}$.

TABLE 5. Comparison of lowest vs highest quartile of plasma cortisol

\begin{tabular}{|c|c|c|c|}
\hline Variable & Lowest quartile & Highest quartile & Significance $P$ \\
\hline Age & $39.3 \pm 11.6$ & $28.8 \pm 7.8$ & $<0.001$ \\
\hline BMI $\left(\mathrm{kg} / \mathrm{m}^{2}\right)$ & $26.9 \pm 4.4$ & $24.1 \pm 3.0$ & $=0.006$ \\
\hline Systolic (mmHg) & $116 \pm 10$ & $118 \pm 10$ & $=0.572$ \\
\hline Diastolic $(\mathrm{mmHg})$ & $76 \pm 8$ & $75 \pm 9$ & $=0.460$ \\
\hline $\mathrm{FBG} \mathrm{mg} / \mathrm{dL}$ & $83.2 \pm 13.1$ & $80.9 \pm 7.1$ & $=0.376$ \\
\hline FCRS & $1.05 \pm 0.23$ & $1.02 \pm 0.15$ & $=0.566$ \\
\hline F cortisol $(\mu \mathrm{g} / \mathrm{dL})$ & $7.6 \pm 2.2$ & $30.3 \pm 4.3$ & $<0.001$ \\
\hline
\end{tabular}

BMI: body mass index; Waist: waist circumference; Systolic: systolic blood pressure; Diastolic: diastolic blood pressure; FBG: fasting blood glucose; Total chol: total cholesterol; HDL chol: high density lipoprotein cholesterol; FCRS: Framingham Coronary Heart Disease Risk Score; F cortisol: fasting plasma cortisol. 
Troubles in the health care population, as alluded to, are not a novelty, notably with regard to shift-working nurses and physicians however encompassing all categories. Peer and manager pressure in the nosocomial environment have been characterized as akin to mobbing ${ }^{(31)}$. Yet metabolic consequences have rarely been documented, this being to the best of our knowledge, the first protocol to simultaneously address stress, along with nutritional and cardiovascular repercussions.

The finding that reduced body mass index, and improved HDL-cholesterol was associated with more severe stress, and not the opposite. Seems counterintuitive, especially considering the presence of deranged glucose homeostasis in some of the obese, an additional stimulant of both cortisol secretion and cardiovascular disease ${ }^{(8)}$.

Nevertheless it agrees with clinical and epidemiological reports, which define both weight gain and weight loss as alternative effects of the same continuing stress, depending on phenotype and other influences ${ }^{(13,23,24,29)}$.

In a large British cohort of civil servants, stress was associated with weight loss in those that were lean at baseline, and with further obesity in those already affected by such derangement ${ }^{(14)}$. Also in the model of restrained rats, the effect of the experimental HPAA challenge was a craving for palatable feeding (comfort food), which attenuated ACTH response, even though total caloric intake actually diminished. Palatable foods and not necessarily hyperphagia, as described in other series ${ }^{(9,22,24)}$, suppressed the endocrine network, perhaps reducing the feeling of stressors ${ }^{(10)}$.

One should not overlook certain protective features of the job ecosystem itself. Health care workers engaged in diagnosis and assessment (physicians and registered nurses) are less prone to obesity, risks being elevated mainly for technologists, technicians, and service occupations ${ }^{(16)}$. A more privileged social and intellectual position, with easy access to medical information, counseling and therapy might offset occupational risks, even in face of overt stress, as appropriate for the current relatively high status population.

As a potential diagnostic bias, applying to certain radiology or dentistry workers, exposure to low frequency electromagnetic fields might interfere with serum cortisol concentration, rendering more difficult the interpretation in such persons ${ }^{(21)}$.

The lack of ominous nutritional and metabolic connotations, should not be construed as entirely reassuring in this experience, as increased responsivity of HPAA and heightened stress admittedly predispose to psychological morbidity,

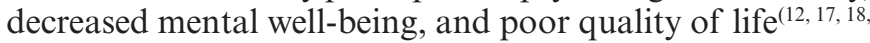
$20,24,25,31)$. Cardiovascular risk remained stable when high and low stress quartiles were compared, a not so encouraging outcome, if reduced BMI and waist circumference along with increased HDL-cholesterol are factored. This population was older, and minor differences in smoking and other variables could be sufficient to hinder any FCRS advantage ${ }^{(3,28,29)}$.

A recent meta-analysis involving more than 200000 individuals ${ }^{(15)}$ did not address stress markers, only working hours. Subjects whose job activities encompassed more than 55 hours/week, as relatively common in the health care professions, but also in other contexts, suffered elevated risk of acquiring type 2 diabetes mellitus. Interestingly, this increased chance was much weaker in those of high social class, being especially prominent in the low socioeconomic stratus, even after adjusting for age, body mass index, physical activity, alcohol and smoking.

This study suffers from weaknesses. Only morning cortisol was registered, not circadian profile, or specific stimulation and suppression maneuvers ${ }^{(6,8,24,27)}$. Urinary, salivary or hair cortisol were not monitored, nor epinephrine, norepinephrine, cytokines or other biomolecules ${ }^{(6,10,19,26)}$. Psychological stress and mental health questionnaires were not part of the protocol, nor was long-term nutritional, metabolic or cardiovascular follow-up. The strengths of the investigation are the rigorous inclusion and exclusion criteria, as well as the objective documentation of the selected variables.

In synthesis, it can be affirmed that even though participants with the highest stress exhibited more favorable BMI and waist circumference, the general metabolic profile of the population was not ideal. Participants suffered from comparatively high indexes of sedentarism, overweight and deranged glucose homeostasis, thus rendering them vulnerable to future cardiovascular and diabetes complications.

As continuing professional strain and burn out encompass a wide range of deleterious connotations, initiatives are advisable to improve stress monitoring, whereas strategies should be implemented to defuse the damaging somatic and neuropsychological dysfunctions. Prescription errors and other risks for patients should be highlighted, as a result of stress-related cognitive impairment, and poor decision making $(17,20,25)$.

The building of positive and nurturing professional relationships across all hierarchical levels, should be a priority at Gastroenterology Services. Along with manageable schedules and workloads, within a comfortable environment, they should foster resilience, enhance job control, and improve optimism and quality of life ${ }^{(12)}$. Also from the points of view of organizational efficiency (increased productivity), patient safety (less technical errors) and staff morale (a healthier workplace), such policies are likely to be beneficial and cost/ effective ${ }^{(18)}$.

\section{ACKNOWLEDGMENTS}

An Investigator Grant to Faintuch J (CNPq 302915/2011-7) is appreciated. The responsible biostatistician is a co-author of this study (Soares RM).

\section{Authors' contributions}

All the authors equally contributed to the study, reviewed the final version, and are responsible for the text. 
Guerra A, Soares RM, Pezzi F, Karkow FJ, Faintuch J. Correlações nutricionais, metabólicas e cardiovasculares do cortisol matutino em profissionais da saúde de um Serviço de Gastroenterologia. Arq Gastroenterol. 2015,52(2):88-93.

RESUMO - Contexto - O estresse no ambiente de trabalho tem sido associado com obesidade. Peso corporal diminuído também tem sido relatado em algumas circunstâncias. Objetivo - Numa casuística de profissionais da saúde, o cortisol matutino foi comparado com variáveis nutricionais e metabólicas, objetivando identificar as correlações de tal marcador. Métodos - A população com n=185; 33,8 $\pm 9,8$ anos; 88,1\% mulheres, índice de massa corporal (IMC) $25.6 \pm 4.4 \mathrm{~kg} / \mathrm{m}^{2}$, incluía enfermeiros e outros funcionários nosocomiais, em sua maioria (75,2\%) com nível sócio-econômico elevado. Os participantes foram estatrificados de acordo com IMC, glicemia de jejum, e síndrome metabólica. O cortisol de jejum e o escore Framingham de risco cardiovascular foram registrados. Resultados - O cortisol médio era aceitável (19.4 $\pm 7.9 \mu \mathrm{g} / \mathrm{dL})$, todavia com valores elevados em $21,6 \%$. A glicemia de jejum e a síndrome metabólica não exibiram correlação, sendo que no tocante ao IMC, os não obesos (IMC $<25)$ apresentaram o cortisol mais alto $(P=0,049)$. Comparando-se os quartis superior e inferior do cortisol, confirmou-se o vínculo com o IMC e perímetro abdominal mais baixos, com escore Framingham de risco cardiovascular inalterado. Conclusão - O cortisol alterado concentrou-se nos casos de IMC mais reduzido. A despeito do baixo IMC e perímetro abdominal, esta população não se beneficiou de escore Framingham de risco cardiovascular menor, sugerindo que, mesmo na ausência de obesidade, este grupo estava exposto a elevado risco cardiovascular, ao lado do estresse. Iniciativas direcionadas para melhor saúde organizacional e da equipe de profissionais, são recomendáveis no ambiente hospitalar.

DESCRITORES - Hidrocortisona. Doenças metabólicas. Obesidade. Pessoal de saúde. Esgotamento profissional.

\section{REFERENCES}

1. Alberti KG, Zimmet P, Shaw J. IDF Epidemiology Task Force Consensus Group. The metabolic syndrome: a new worldwide definition. Lancet. 2005;366(9491):1059-62.

2. American Diabetes Association. Diagnosis and classification of diabetes mellitus Diabetes Care. 2010;33(Suppl 1):S62-S69.

3. Backé EM, Seidler A, Latza U, Rossnagel K, Schumann B. The role of psychosocial stress at work for the development of cardiovascular diseases: a systematic review. Int Arch Occup Environ Health. 2012;85(1):67-79.

4. Baudrand R, Dominguez JM, Carvajal CA, Riquelme A, Campino C, Macchiavello $\mathrm{S}$, et al. Overexpression of hepatic $5 \alpha$-reductase and $11 \beta$-hydroxysteroid dehydrogenase type 1 in visceral adipose tissue is associated with hyperinsulinemia in morbidly obese patients. Metabolism. 2011;60(12):1775-80.

5. Bennett GG, Wolin KY, James SA. Lifecourse socioeconomic position and weight change among blacks: The Pitt County study. Obesity (Silver Spring). 2007;15(1):172-81

6. Bose M, Oliván B, Laferrère B. Stress and obesity: the role of the hypothalamic-pituitary-adrenal axis in metabolic disease. Curr Opin Endocrinol Diabetes Obes. 2009;16(5):340-6.

7. Brasil. Ministério da Saúde [Internet]. Estimativas de População. Brasília: 2014. [update 2014 January 12]. Available from: www.ibge.gov.br/home/estatistica/ populacao/

8. Bruehl H, Rueger M, Dziobek I, Sweat V, Tirsi A, Javier E, et al. Hypothalamic-pituitary-adrenal axis dysregulation and memory impairments in type 2 diabetes. $\mathrm{J}$ Clin Endocrinol Metab. 2007;92(7):2439-45.

9. Buss J. Associations between obesity and stress and shift work among nurses. Workplace Health Saf. 2012;60(10):453-8.

10. Foster MT, Warne JP, Ginsberg AB, Horneman HF, Pecoraro NC, Akana SF, Dallman MF. Palatable foods, stress, and energy stores sculpt corticotropin-releasing factor, adrenocorticotropin, and corticosterone concentrations after restraint. Endocrinology. 2009;150(5):2325-33.

11. Gariepy G, Wang J, Lesage A, Schmitz N. The interaction of obesity and psychological distress on disability. Soc Psychiatry Psychiatr Epidemiol. 2010;45(5):531-40.

12. Jackson D, Flirtko A, Edenborough M. Personal resilience as a strategy for surviving and thriving in the face of workplace adversity: a literature review. J Adv Nurs. 2007;60(1):1-9.

13. Jacobson IG, Smith TC, Smith B, Keel PK, Amoroso PJ, Wells TS, B et al. Disordered eating and weight changes after deployment: longitudinal assessment of a large US military cohort. Am J Epidemiol. 2009;169(4):415-27.

14. Kivimäki M Head J, Ferrie JE, Shipley MJ, Brunner E, Vahtera J, Marmot MG. Work stress, weight gain and weight loss: evidence for bidirectional effects of job strain on body mass index in the Whitehall II study. Int J Obes (Lond). 2006;30(6):982-7.

15. Kivimäki M, Virtanen M, Kawachi I, Nyberg ST, Alfredsson L, Batty GD, et al Long working hours, socioeconomic status, and the risk of incident type 2 diabetes: a meta-analysis of published and unpublished data from 222120 individuals. Lancet Diabetes Endocrinol. 2015;3(1):27-34
16. Lee DJ, Fleming LE, LeBlanc WG, Arheart KL, Ferraro KF, Pitt-Catsouphes $\mathrm{M}$, et al. Health status and risk indicator trends of the aging US health care workforce. J Occup Environ Med. 2012;54(4):497-503.

17. Machi MS, Staum M, Callaway CW, Moore C, Jeong K, Suyama J, Patterson PD, Hostler D. The relationship between shift work, sleep and cognition in career emergency physicians. Acad Emerg Med. 2012;19(1):85-91.

18. McNeely E. The consequences of job stress for nurses' health: time for a check-up Nurs Outlook. 2005;53(6):291-9.

19. Meyer JS, Novak MA. Minireview: Hair cortisol: a novel biomarker of hypothalamic-pituitary-adrenocortical activity. Endocrinology. 2012;153(9):4120-7.

20. Mion G, Ricouard S. [Rest for safety: which stakes?] Ann Fr Anesth Reanim. 2007;26(7-8):638-48.

21. Mortazavi SM, Vazife-Doost S, Yaghooti M, Mehdizadeh S, Rajaie-Far A Occupational exposure of dentists to electromagnetic fields produced by magnetostrictive cavitrons alters the serum cortisol level. J Nat Sci Biol Med. 2012;31(1):60-4

22. Nevanperä NJ, Hopsu L, Kuosma E, Ukkola O, Uitti J, Laitinen JH. Occupational burnout, eating behavior, and weight among working women. Am J Clin Nutr. 2012;95(4):934-43.

23. Nyberg ST, Heikkilä K, Fransson EI, Alfredsson L, De Bacquer D, Bjorner JB, et al. Job strain in relation to body mass index: pooled analysis of 160000 adults from 13 cohort studies. J Intern Med. 2012;272(1):65-73.

24. Roberts C, Troop N, Connan F, Treasure J, Campbell IC. The effects of stress on body weight: biological and psychological predictors of change in BMI. Obesity (Silver Spring). 2007:15(12):3045-55.

25. Starcke K, Brand M. Decision making under stress: a selective review. Neurosci Biobehav Rev. 2012;36(4):1228-48.

26. Szabo S, Tache Y, Somogyi A. The legacy of Hans Selye and the origins of stress research: a retrospective 75 years after his landmark brief "letter" to the editor of nature. Stress. 2012;15(5):472-8.

27. Ulhôa MA, Marqueze EC, Kantermann T, Skene D, Moreno C. When does stress end? Evidence of a prolonged stress reaction in shiftworking truck drivers Chronobiol Int. 2011;28(9):810-8.

28. Vogelzangs N, Beekman AT, Milaneschi Y, Bandinelli S, Ferrucci L, Penninx BW Urinary Cortisol and Six-Year Risk of All-Cause and Cardiovascular Mortality. J Clin Endocrinol Metab. 2010;95(11):4959-64.

29. Walker BR, Soderberg S, Lindahl B, Olsson T. Independent effects of obesity and cortisol in predicting cardiovascular risk factors in men and women. J Intern Med. 2000;247(2):198-204

30. Wilson PW, D'Agostino RB, Levy D, Belanger AM, Silbershatz H, Kannel WB Prediction of coronary heart disease using risk factor categories. Circulation. 1998;97(18):1837-74.

31. Yildirim A, Yildirim D. Mobbing in the workplace by peers and managers: mobbing experienced by nurses working in healthcare facilities in Turkey and its effect on nurses. J Clin Nurs. 2007;16(8):1444-53.

Received 12/10/2014 Accepted 18/12/2014 